por volta de 1929; até então, no Uruguai, "ninguém conhecia essas questões pela forma que êle as tratava"; foi orientado em suas pesquisas "sobretudo pela leitura de cientistas brasileiros - Nina Rodrigues e Artur Ramos" (pág. 21). Seus principais trabalhos de folclore e etnografia (pois como poeta e ensaista, fora dêsses setores, sua obra é muito vasta) são: "El Negro Rioplatense y otros ensayos" (1937); "Linea de Color" (1938); "Negros Esclavos y Negros Libres". Escritos não só com intuito cientifico, mas também com vistas à divulgação, tiveram, sob êste aspecto, indiscutivel exito.

São êstes os quatro livros que Carvalho Neto analisa e critica, seguindo Valdés passo a passo, apontando lacunas e falhas. Mas ao mesmo tempo completa-os indicando obras que exprimam mais claramente o que Valdés não soube desenvolver; localizando fontes e dados, pois Valdés, como muitos autodidatas, não tinha o hábito da citação precisa; comparando as traduções com as fontes para apontar as liberdades poéticas tomadas com os textos. Mostra assim o crítico não somente um conhecimento profundo das obras analisadas, mas também a familiaridade com vasta bibliografia estrangeira. O á-vontade com que se refere a historiadores e antropólogos brasileiros dá bem uma noção de sua cultura nesse setor.

Poeta de talento, Valdés não conseguiu evitar que sua obra se ressentisse tanto da visão poética das coisas, quanto de suas convicçoes marxistas, que the comprometem a objetividade dos trabahos. Alguns de seus ansaios sôbre assuntos negros brasileiros, por exemplo, "ultrapassam todos os outros, até agora, em matéria de estilização literária" e neles a llivulgação que Valdés pretendia "se revestiu de forma lírica" (pág. 55). Nos artigos sôbre o problema negro nos Estados Unidos, Valdés "retoma os clamores de suas convicções políticas" (pág. 72).

Revelam as obras de Valdés a grande influência da Antropologia Cultural brasileira nos autores uruguaios; e se Valdés teve como principais inspiradores a Nina Rodrigues e Artur Ramos, o seu crítico, conhecedor que é idos estudos brasileiros, lamenta não tenha êle conseguido a objetividade dos antropólogos brasileiros que o inspiraram.

A crítica é, sem dúvida, exaustiva, embora dirigida quase ùnicamente para a correção dos dados e a localização das fontes; quando se apontam os quadros de referência com que Valdés encarou a realidade, é apenas para mostrar a pouca objetividade, e nunca para discutir a validade dos pontos de apôio. Falta, também, a síntese das principais direções do pensamento de Valdés e a localização de sua obra no contexto dos estudos antropológicos uruguaios. No entanto, o livro é de indiscutível utilidade para quem necessite recorrer à obra de Valdés, pois nele encontrará as informações suplementares para preencher as lacunas devidas à falta de formação científica dêste precursor.

\title{
Maria Isaura Pereira de Queiroz
}

THALES DE AZEVEDO: O Catolicismo no Brasil. 70 págs. Os Cadernos de Cultura. Ministério de Educação e Cultura. Rio de Janeiro, 1955 .

A objetividade dêste trabalho, que é testemunho a um tempo fidedigno e desapaixonado, em nada ficou prejudicada pela formação cato- 
lica do autor. Procura êle, através de observaçóes pessoais e de pesquisa bibliográfica, delinear as principais características do catolicismo brasileiro.

A afirmação de que o Brasil é "a maior nação católica de nossos tempos", baseada nas respostas ao censo de 1940 (pág. 18), tem sentido estatístico apenas, pois se considerarmos o critério de freqüência à missa e aos sacramentos, utilizado pela Igreja na avaliação đa fé, o número de verdadeiros católicos sofre boa redução. O catolicismo brasileiro é predominantemente de caráter festivo, tendo muita importância as novenıs, as procissões, as romarias a santuários, as promessas propiciatórias arss santos (pág. 28); o católico brasileiro comum se contenta com frequentá-las e promover o batizado dos filhos, o casamento na igreja, e as exéquias católicas para seus mortos (pág. 59).

Os traços peculiares do catolicismo brasileiro, que corroboram êste aspecto antes formal do que de verdadeira adesão intima e que acompanham o caráter primordial de festa que forma a sua essência, são vários. Em primeiro lugar, "o grande escândalo do catolicismo brasileiro" é a falta de vocações sacerdotais, notada em todo o país desde a época colonial (pág. 42); a ela corresponde a dificuldade, também histórica, de se obter do povo o pagamento das espórtulas (págs. 42-48, 53). Notase, ademais, freqüentemente franco sincretismo com crenças indígenas, africanas e espíritas (págs. 29-30, 34-35, 62-63). Falta quase a função de contrôle social, evidenciado pela pouca importância dada ao casamento na igreja, principalmente nas camadas populares (págs. 38-39), e pelo pouco pêso que conselhos e indicações da Igreja têm tido nos pleitos eleitorais (págs. 23, 57). Além disso, o número de estudantes inscritos na Juventude Universitária Católica "é também comparativamente rehluzido" (pág. 57) e a imprensa católica, isto é, subvencionada pela Igreja ou por agremiações religiosas, é pràticamente inexistente (pág. 41). Finalmente, os próprios católicos praticantes são muito ignorantes de coisas de religião, pois sua instrução se cifra na preparação para a primeira comunhão (pág. 55) .

Foi a falta de padres, desde os tempos da colonização, que deu ao catolicismo brasileiro êsse aspecto; o povo formou "com elementos do dogma e da liturgia católica, sua própria religião” (pág. 61).

Deplora Thales de Azevedo que êsse catolicismo, cuja independência em relação à hierarquia é manifesta, não tenha até hoje despertado interêsse idêntico ao que a Antropologia e a Etnografia vêm demonstrando pelas religiões indígenas e africanas, e espera que seu trabalho contribua para despertá-lo, como para colocar em suas devidas proporções certos estereótipos que não correspondem à realidade (pág. 15). O ensaio levanta, com efeito, problemas que desafiam a curiosidade dos especialistas. Por outro lado, se entre nós a Sociologia religiosa ainda está nos primórdios, o mesmo acontece com outros setores das ciências sociais; o autor reconhece, aliás, que os estudiosos da realidade brasileira têm sempre que "valer-se dos seus próprios recursos para construir de base, porque pràticamente nada havia sôbre o assunto" (pág. 4). Dêsse ponto de vista, os trabalhos de Sociologia religiosa no Brasil estão antes em situação privilegiada, pois alguns de seus aspectos, notadamente os que se relacionam com o fanatismo, têm merecido atenção e estudos. E' verdade que o fenômeno é considerado "aberrante", mas nem por isso deixa de constituir um dos traços peculiares de nosso catolicismo e em stia análise o ponto de vista sociológico tem sido utilizado, com maior ou 
menor felicidade, desde "Os Sertões" de Euclides da Cunha. Quanto às práticas cotidianas, o seu estudo também em países de mais antiga tradição sociológica é muito recente, não sendo de estranhar o seu atraso entre nós.

Sob êsse aspecto principalmente é de grande valor a contribuiçio de Thales de Azevedo; apresentando uma bibliografia interessante e pouco conhecida, apontando questóes e problemas, numa análise sucinta más objetiva, vem indicar caminhos novos aos estutlos de Sociologia religiosa no Brasil.

\section{Maria Isalura Pereira de Qneiroz}

RAFAEL GIRARD: Los Chortis ante el Problema Maya. Historia de las Culturas Indigenas de América, desde su Origen hasta Hoy. 5 volumes com 400 fotografias, 16 mapas, 3 diagramas, 16 pranchas e 9 plantas. Antigua Librería Robredo. México, 1949.

Os ambiciosos propósitos desta volumosa obra já vêm consignados no titulo e no subtitulo. Pretende o autor ter encontrado, através de suas pesquisas etnográficas entre os Chortí contemporâneos, o instrumento analítico que the permite desvendar os significados reconditos dos monumentos e documentos legados pelos Maya primitivos. De posse dos dados assim obtidos, retraça a evolução da totalidade das culturas indigenas das Américas, resolvendo de passo todos os problemas ainda hoje abertos à discussão.

O primeiro volume, na introdução, situa os Chortí na área cultural Maya, cujos limites e posição ecológica são estabelecidos; vêm em segui da os capitulos consagrados à antropologia física, ao idioma Chortí e sua posição histórico-lingüística, à etnografia, terminando pela descrição de auto popular, a "Dança dos Gigantes", em que o autor vê uma dramatização de episódios do Popol Vuh. Os volumes segundo e terceiro têm por objeto diferentes aspectos da religião Maya, o calendário sagrado, os ritos, os templos, a casta sacerdotal, a magia do govêrno das chuvas, a cosmogonia, a teogonia, o simbolismo dos monumentos arqueológicos, dos tecidos e da cerâmica. O volume quarto contém dois capitulos, "Esoterismo del Popol Vuh", e "Etnografía y Religión Comparadas", que inicia o confronto das culturas ameríndias, completado no volume quinto, cujo único capitulo se intitula "Arqueología e Historia".

Em primeira abordagem, o estudo do Sr. Rafael Girard se nos afigura promissor. A reconstrução histórica a partir de dados etnográficos é um método atraente e engenhoso; os frutos que dêle se podem tirar estão exemplificados no trabalho clássico de Sapir, "Time Perspective in Aboriginal American Cultures". A cultura Maya constitui um caso particularmente favorável à aplicação do método, pois que as massas camponesas que habitam hoje o Iucatã e os altiplanos da Guatemala e de Honduras Ocidental conservaram grande parte do estilo de vida do passado, o que se acha amplamente documentado nos monumentos arqueológicos e nas fontes históricas. Mas o nosso autor atribui aos fenomenos culturais uma rigidez na persistência que não faz justiça aos fatos. Tudo o que ocorreu na Mesoamérica depois da conquista espanhola èle considera negligenciável, a superficie de um palimpsesto a ser raspada para se descobrir o 